\title{
Reviewing the potential role of radiation therapy in gallbladder cancer: an update
}

\author{
Divyesh Kumar, Nali Muni Kiran, Divya Khosla \\ Department of Radiotherapy and Oncology, Postgraduate Institute of Medical Education and Research, Chandigarh, India
}

Received: July 28, 2021

Revised: October 15, 2021

Accepted: October 26, 2021

\author{
Correspondence: \\ Divyesh Kumar \\ Department of Radiotherapy and \\ Oncology, Postgraduate Institute of \\ Medical Education and Research, \\ Chandigarh 160012, India. \\ Tel: +91-172-2756284 \\ E-mail: divyeshanand1@gmail.com \\ ORCID: \\ https://orcid.org/0000-0002-4277-9572
}

Gallbladder cancer is a highly malignant disease with a poor prognosis. It is the most common cancer of the biliary tract pathway. Although surgery remains the treatment of choice for early-stage disease, majority of the patients presents in locally advanced, unresectable and metastatic stage of the disease. Radiotherapy and chemotherapy thus form an integral part of management for these locally advanced staged patients. The role of radiation though has been advocated in gallbladder cancer, majorly in the adjuvant setting, its role in neoadjuvant and palliative settings remains in an evolving phase. The article thus aims to review and update the existing literature regarding the role of radiation therapy in gallbladder cancer.

Keywords: Gallbladder cancer, Radiation therapy, Review, Chemotherapy

\section{Introduction}

The gallbladder is a small pear-shaped organ that lies underneath the liver and stores bile. Despite being a small organ there is a high chance of malignancy reported. The absence of the serosa layer, proximity to critical adjoining structures, and easy extension to lymphatics makes it vulnerable for early dissemination. Often, patients present in an advanced stage of the disease, with disseminated metastasis being reported in the range of $65 \%$ to $82 \%$, for hematological metastasis and 91\% to $94 \%$ for lymphatic metastasis, respectively $[1,2]$. Although its incidence in Western countries is less, it is quite prevalent in Asian counties with a high prevalence seen amongst obese females with a personal or family history of gallstones and ill-defined genetic variants [3]. According to GLOBOCAN 2020 data [4], gallbladder cancer (GBC) is the 23rd most incident but 20th most deadly cancer worldwide.

Depending upon the stage of the disease, surgery, radiotherapy (RT), and chemotherapy are the modalities of treatment used for
GBC. Although surgical treatment remains the only curative treatment for early-stage GBC, most of the patients present in locally advanced or metastatic stages of the disease, requiring RT and chemotherapy as an adjunct to a definitive modality or as palliative therapy.

With the advancement in technology, RT techniques have evolved over the years from two-dimensional (2D) techniques to intensity-modulated radiation therapy (IMRT) and volumetric modulated arc therapy (VMAT). Lately, not much about its role in GBC have been reviewed. The present article thus aims to review the role of RT as used in the past and its usage during the present era.

\section{Role as Adjuvant Therapy}

In $\mathrm{GBC}$, the outcomes are poor, even after complete resection with high rates of both local and distant relapses. The relapse rates are high, especially in $\geq T 3$, and in node-positive disease [5,6]. Adjuvant therapy is indicated in patients with completely resected muscle-in-

Copyright (C) 2022 The Korean Society for Radiation Oncology

This is an Open Access article distributed under the terms of the Creative Commons Attribution Non-Commercial License (http://creativecommons.org/licenses/by-nc/4.0/) which permits unrestricted non-commercial use, distribution, and reproduction in any medium, provided the original work is properly cited. 
vasive disease, node-positive disease, and margin-positive GBC.

Various studies have advocated the role of adjuvant RT, as shown in Table 1 [7-24]. The benefit of the adjuvant RT was first reported by Bosset et al. [7]; five patients out of seven were alive after a median follow-up of 5 months in their study. The support for adjuvant therapy is further derived from a few population-based stud- ies and SEER database demonstrating the benefit of chemoradiotherapy (CRT) over chemotherapy alone in T2 or above; or node-positive patients. SWOG 0809 trial [18] published in 2015 has evaluated the role of adjuvant chemotherapy followed by RT in extrahepatic biliary cancers and GBC in a phase II trial. In this trial, patients received gemcitabine injection $1,000 \mathrm{mg} / \mathrm{m}^{2}$ on D1 and D8

Table 1. Studies favouring adjuvant radiotherapy \pm chemotherapy

\begin{tabular}{|c|c|c|c|c|c|}
\hline Study, year & Type & $n$ & Characteristic & Treatment received & Outcome \\
\hline Bosset et al. [7], 1989 & Retrospective & 7 & $\begin{array}{l}\text { Liver adhesions: } 6 \text { (85.7\%) } \\
\text { Portal vein adhesions: } 1 \text { (14.2\%) }\end{array}$ & RT 46 Gy & $5 / 7$ patients alive at 5 months \\
\hline Kresl et al. [8], 2002 & Retrospective & 21 & $\begin{array}{l}\text { T1b: } 1(4.7 \%) \\
\text { T2: } 6(28.5 \%) \\
\text { T3: } 9(42.8 \%) \\
\text { T4: } 5(23.8 \%) \\
\text { N0: } 7(33.3 \%) \\
\text { N1: } 7(33.3 \%) \\
\text { N2: } 7(33.3 \%)\end{array}$ & $\begin{array}{l}54 \text { Gy RT median dose with con- } \\
\text { current 5FU }\end{array}$ & 5-yr OS: $64 \%$ \\
\hline Lindell et al. [9], 2003 & Retrospective & 20 & $\begin{array}{l}\text { Stage I (10\%) } \\
\text { Stage II (30\%) } \\
\text { Stage III (25\%) } \\
\text { Stage IV (35\%) }\end{array}$ & $\mathrm{EBRT} \pm \mathrm{IORT}$ & $\begin{array}{l}5-y r \text { OS: } 47 \% \text { in RT group vs. } \\
13 \% \text { in observation group }\end{array}$ \\
\hline Czito et al. [10], 2005 & Retrospective & 22 & $\begin{array}{l}\text { T2N0M0: } 2(9.09 \%) \\
\text { T3N0M0: } 4(18.1 \%) \\
\text { T4N0M0: } 1(4.5 \%) \\
\text { T2N1M0: } 7(31.8 \%) \\
\text { T3N1M0: } 1(4.5 \%) \\
\text { T4N2M0: } 1(4.5 \%) \\
\text { T2NxM0: } 1(4.5 \%) \\
\text { T3NxM0: } 3(13.6 \%) \\
\text { T4NxM0: } 1(4.5 \%) \\
\text { TxN2M0: } 1(4.5 \%)\end{array}$ & 45 Gy RT with concurrent 5FU & $\begin{array}{l}\text { 5-yr OS: } 37 \% \\
5-y r \text { DFS: } 33 \%\end{array}$ \\
\hline $\begin{array}{l}\text { Balachandran et al. [11], } \\
2006\end{array}$ & Retrospective & 117 & $\begin{array}{l}\text { T1: } 14(11.9 \%) \\
\text { T2: } 23(19.6 \%) \\
\text { T3: } 68(58.1 \%) \\
\text { T4: } 12(10.2 \%) \\
\text { N0: } 18(15.38 \%) \\
\text { N1: } 56(47.86 \%) \\
\text { Nx: } 43(36.75 \%)\end{array}$ & CRT & $\begin{array}{l}24 \text { months OS with CRT vs. } 11 \\
\text { months with observation }\end{array}$ \\
\hline Gold et al. [12], 2009 & Retrospective & 73 & $\begin{array}{l}\text { T1: } 16 \text { (22\%) } \\
\text { T2: } 40(55 \%) \\
\text { T3: } 17(23 \%) \\
\text { N0: } 40(55 \%) \\
\text { N1: } 20(27 \%) \\
\text { Nx: } 13(18 \%)\end{array}$ & $\begin{array}{l}\text { 50.4 Gy RT median dose with con- } \\
\text { current 5FU }\end{array}$ & $\begin{array}{l}\text { No difference in OS between } \\
\text { CRT and observation }\end{array}$ \\
\hline Kim et al. [13], 2012 & Retrospective & 47 & $\begin{array}{l}\text { T2: } 18(55.6 \%) \\
\text { T3-4: } 29(36.8 \%) \\
\text { N0: } 17(41.2 \%) \\
\text { N1: } 20(54.0 \%) \\
\text { Nx: } 10(25.0 \%)\end{array}$ & 40-50 Gy RT with concurrent 5FU & $\begin{array}{l}5-\mathrm{yr} \text { OS: } 43.7 \%(52.8 \% \text { in R0 } \\
\text { and 20\% in R1) }\end{array}$ \\
\hline Muller et al. [14], 2013 & Retrospective & 46 & $\begin{array}{l}\text { IA (T1N0): } 3 \text { (7\%) } \\
\text { IB (T2N0): } 14(30 \%) \\
\text { IIA (T3N0): } 10(22 \%) \\
\text { IIB (T1-3N1): } 18(39 \%) \\
\text { III (T4N0-1): } 1(2 \%)\end{array}$ & 45-54 Gy with concurrent 5FU & $\begin{array}{l}\text { 5-yr OS: 38.5\% for RT alone, } \\
\text { 56\% for CRT }\end{array}$ \\
\hline
\end{tabular}


Table 1. Continued

\begin{tabular}{|c|c|c|c|c|c|}
\hline Study, year & Type & $n$ & Characteristic & Treatment received & Outcome \\
\hline Jeong et al. [15], 2014 & Retrospective & 86 & $\begin{array}{l}\text { T1b (1\%) } \\
\text { T2 (45\%) } \\
\text { T3 (47\%) } \\
\text { N+ (33\%) } \\
\text { R0 (84\%) } \\
\text { R1 (16\%) }\end{array}$ & 43.2-60 Gy RT with chemotherapy & $\begin{array}{l}\text { 5-yr LRC: } 73 \% \\
\text { 5-yr DFS: } 36 \% \\
\text { 5-yr OS: } 42 \%\end{array}$ \\
\hline Hyder et al. [16], 2014 & SEER database & 5,011 & $\begin{array}{l}\text { In situ/limited to serosa: } 3,758 \\
(75.0 \%) \\
\text { Extension to liver: } 570(11.4 \%) \\
\text { Extension to any other or } \\
\text { multiple organs: } 683(13.6 \%) \\
\text { N0: } 3,190(63.7 \%) \\
\text { N1: } 959(19.1 \%) \\
\text { Nx: } 862(17.2 \%)\end{array}$ & No specific options & $\begin{array}{l}\text { With RT, at } 1 \text {-year improved } \\
\text { survival ( } p<0.001) \text {, though at } \\
5 \text { years no benefit observed ( } p \\
=0.50 \text { ) }\end{array}$ \\
\hline Wang et al. [17], 2015 & Retrospective & 112 & $\begin{array}{l}\text { T1/T2 (58.9\%) } \\
\text { T3/T4 (41.1\%) } \\
\mathrm{N}+(44.6 \%) \\
\text { R0 (74\%) } \\
\text { R1 }(26 \%)\end{array}$ & $\begin{array}{l}\text { Median dose of } 50.4 \text { Gy RT with } \\
\text { 5FU/gemcitabine/capecitabine } \\
\text { chemotherapy }\end{array}$ & $\begin{array}{l}\text { Decreased local failure and } \\
\text { similar OS with RT }\end{array}$ \\
\hline $\begin{array}{l}\text { Ben-Josef et al. [18], } \\
2015\end{array}$ & Prospective & 79 & $\begin{array}{l}\text { Stage II (13.9\%) } \\
\text { Stage III (63.9\%) } \\
\text { R0 (68\%) } \\
\text { R1 (32\%) }\end{array}$ & $\begin{array}{l}\text { 45-59.4 Gy RT with concurrent } \\
\text { capecitabine, followed by gem- } \\
\text { citabine/capecitabine }\end{array}$ & $\begin{array}{l}2-y r \text { DFS: } 52 \% \\
2-y r \text { OS: } 56 \%\end{array}$ \\
\hline Kim et al. [19], 2016 & Retrospective & 291 & $\begin{array}{l}\text { T Stage 1: } 24(9.1 \%) \\
\text { T Stage 2: } 122(46.2 \%) \\
\text { T Stage 3: } 102(38.6 \%) \\
\text { T Stage 4: } 16(6.1 \%) \\
\text { N0: } 141(48.5 \%) \\
\text { N1: } 110(37.8 \%) \\
\text { Nx: } 40(13.7 \%) \\
\text { R0: } 250(86 \%) \\
\text { R1: } 41(14 \%)\end{array}$ & $\begin{array}{l}\text { RT with gemcitabine-based che- } \\
\text { motherapy }\end{array}$ & $\begin{array}{l}\text { Compared to surgery, with adju- } \\
\text { vant treatment (CT/CRT) high- } \\
\text { er DFS and OS observed, espe- } \\
\text { cially with high-risk features } \\
(\mathrm{T} 3 / \mathrm{T} 4, \mathrm{LN}+, \mathrm{R}+)\end{array}$ \\
\hline $\begin{array}{l}\text { Mantripragada et al. [20], } \\
2017\end{array}$ & $\begin{array}{l}\text { National Cancer } \\
\text { Database }\end{array}$ & 4,775 & $\begin{array}{l}\text { T2No/x: Adj CT }(381,16.6 \%), \\
\text { no Adj CT }(1,920,83.4 \%) \\
\text { T3No/x: Adj CT }(338,34.4 \%), \\
\text { no Adj CT }(644,65.6 \%) \\
\text { T1-3N1-2: Adj CT }(654,43.8 \%), \\
\text { no Adj CT }(38,56.2 \%) \\
\text { Ro (76\%) } \\
\text { R+ (34\%) }\end{array}$ & $\begin{array}{l}50.4 \text { Gy RT median dose with che- } \\
\text { motherapy }\end{array}$ & No difference in OS with RT \\
\hline Kim et al. [21], 2018 & Meta-analysis & 9,364 & - & Unspecified & $\begin{array}{l}\text { RT increases DFS and OS, } \\
\text { increased benefit of RT in LN+ } \\
\text { disease }\end{array}$ \\
\hline Ren et al. [22], 2020 & Meta-analysis & 1,465 & - & Unspecified & $\begin{array}{l}\mathrm{RT} \text { increases } 5 \text {-yr } 0 \mathrm{~S} \text { and } \\
\text { reduces local recurrence } \\
\text { Highest benefit in } \mathrm{LN}+/ \mathrm{R}+ \\
\text { disease }\end{array}$ \\
\hline Kapoor et al. [23], 2020 & Retrospective & 36 & $\begin{array}{l}\text { T2b: } 13(36.1 \%) \\
\text { T3: } 23(63.9 \%) \\
\text { N0: } 25(69.4 \%) \\
\text { N1: } 10(27.8 \%) \\
\text { N2: } 1(2.8 \%) \\
\text { R0: } 31(86.1 \%) \\
\text { R1: } 5(13.9 \%)\end{array}$ & $\begin{array}{l}\text { Sequential CT (GEMOX, } 2 \text { weekly) } \\
\text { followed by RT ( } 45 \text { Gy/25 frac- } \\
\text { tions over } 5 \text { weeks) }\end{array}$ & $\begin{array}{l}\text { 2-yr OS: } 55.1 \% \\
2-y r \text { RFS: } 44.7 \%\end{array}$ \\
\hline Chen et al. [24], 2021 & Systematic review & 14,646 & - & Unspecified & $\begin{array}{l}\text { 5-yr OS improved with CRT in } \\
L N+/ R+\text { disease }\end{array}$ \\
\hline
\end{tabular}

RT, radiotherapy; 5FU, 5-fluorouracil; OS, overall survival; DFS, disease-free survival; EBRT, external beam radiation therapy; IORT, intraoperative radiotherapy; CRT, chemoradiotherapy; CT, chemotherapy; LN, lymph node; Adj, adjuvant; RFS, relapse-free survival. 
and oral capecitabine $1,500 \mathrm{mg} / \mathrm{m}^{2}$ twice daily for 14 days for 4 cycles. This was followed by RT (54-59 Gy to the tumor bed and 45 Gy to the nodal regions) along with concurrent capecitabine 1,330 $\mathrm{mg} / \mathrm{m}^{2}$ daily. With a median follow-up of 35 months, overall survival (OS) was 65\% (67\% in the R0 group and 60\% in the R1 group). Though there was no head-to-head comparison with patients receiving chemotherapy alone or patients kept on observation, the local recurrence was $11 \%$ in this study, compared to the 16\%-30\% estimated risk of local recurrence in patients receiving no adjuvant therapy. However, approximately $52 \%$ of the patients had developed grade 3 adverse events and 14\% had developed grade 4 adverse events [8-20].

Further, in a meta-analysis conducted by Kim et al. [21] and Ren et al. [22], the patients with node-positive and margin-positive disease derived clear survival benefits from adjuvant therapy. Kapoor et al. [23] concluded in their study that sequential CRT without concurrent RT could be a better-tolerated regimen, at the cost of lower survival rates. In a systematic review conducted by Chen et al. [24], the benefit was seen in patients with node-positive or margin-positive status.

Though three-dimensional (3D) CRT is the most common modality used in the RT of gall bladder malignancies in the adjuvant setting, the use of other techniques like IMRT, stereotactic body radiation therapy (SBRT), and proton beam therapy (PBT) is being investigated. Fuller et al. [25] have reported the use of IMRT with ultrasound guidance for GBC and biliary tract carcinomas. The median dose received was 59 Gy with IMRT versus 48 Gy with conventional RT with lower toxicities and higher median survival in the IMRT arm. Further, in a study done by Gedam et al. [26], VMAT plans were generated for patients already treated by IMRT and they concluded that constant dose rate volumetric modulated arc therapy (CDR-VMAT) could be a valid option in patients of GBC planned for RT.
Although the role of brachytherapy is not well established in GBC, Kurisu et al. [27] in their case report highlighted the usage of high-dose-rate intraluminal brachytherapy (HDRIBT) in post-operated patient of GBC with residual disease. They gave HDRIBT (20 Gy/2 fraction) followed by EBRT of $30 \mathrm{~Gy} / 15$ fraction at an interval of 2 weeks.

Besides it, the role of SBRT in the adjuvant setting has also been evaluated in some case reports $[28,29]$. As it has the potential of delivering higher doses to the tumor at a higher dose per fraction while limiting the dose to organs-at-risk (OAR), its role should further be explored by properly conducted clinical trials.

Similar to SBRT, PBT also provides sharp dose gradients with a high dose to the tumor cells and minimal effects on OAR. Makita et al. [30] have treated 28 patients with cholangiocarcinoma and $\mathrm{GBC}$ with proton therapy. The median radiation dose was $68.2 \mathrm{~Gy}$ radiobiological equivalent (RBE). The 1-year local control, progressive-free survival (PFS), and OS were 67.7\%, 29.5\%, and 49\%, respectively.

Overall, adjuvant RT with or without chemotherapy in its various formats (3DCRT, IMRT, VMAT) plays a crucial role in GBC and is indicated in patients with residual disease, $\geq \mathrm{T} 3$ stage, and with node or margin positive status. The role of SBRT and PBT needs further evaluation.

\section{Role as Definitive Therapy}

With the advent of modern techniques like image guidance, organ motion management, and adaptive planning, delivering a high dose per fraction ablative RT with a high biologically equivalent dose (BED) has become possible. Few retrospective analyses have analysed the use of definitive RT in unresectable cases of GBC, as depicted in Table 2. A SEER database analysis and a National Cancer Database analysis

Table 2. Studies depicting definitive role of RT

\begin{tabular}{|c|c|c|c|c|c|}
\hline Study, year & Type & $n$ & Characteristic & Treatment received & Outcomes \\
\hline \multirow[t]{3}{*}{ Pollom et al. [31], 2017} & \multirow[t]{3}{*}{ SEER medicine database } & \multirow[t]{3}{*}{2,343} & Local disease: 703 (30\%) & Unspecified & \multirow{3}{*}{$\begin{array}{l}\text { Median OS: } 9 \text { months with- } \\
\text { out RT, } 10 \text { months with RT }\end{array}$} \\
\hline & & & Regional disease: 785 (33.5\%) & 45\% Received CT & \\
\hline & & & Distant metastases: 835 (35.6\%) & & \\
\hline \multirow[t]{6}{*}{ Verma et al. [32], 2018} & \multirow[t]{6}{*}{ National Cancer Database } & \multirow[t]{6}{*}{1,199} & Tx: 493 (41.11\%) & Any dose & \multirow{6}{*}{$\begin{array}{l}\text { Median OS: } 8 \text { months with } \\
\text { CT, } 13 \text { months with CRT }\end{array}$} \\
\hline & & & $\mathrm{T} 1 / \mathrm{T} 2: 68$ (5.6\%) & Unspecified & \\
\hline & & & T3/T4: 638 (53.2\%) & & \\
\hline & & & N0: 367 (3.67\%) & & \\
\hline & & & $\mathrm{N}+: 329(27.4 \%)$ & & \\
\hline & & & Nx: 503 (41.95\%) & & \\
\hline \multirow[t]{2}{*}{ Bisello et al. [33], 2019} & \multirow[t]{2}{*}{ Retrospective } & \multirow[t]{2}{*}{77} & \multirow[t]{2}{*}{ Unspecified } & Median 50 Gy & $2-y r$ OS: $26 \%$ \\
\hline & & & & $\begin{array}{l}\text { EBRT + } 14 \text { Gy BT, 5FU/ } \\
\text { gemcitabine }\end{array}$ & 2-yr PFS: 9\% \\
\hline
\end{tabular}

$\mathrm{RT}$, radiotherapy; OS, overall survival; $\mathrm{CT}$, chemotherapy; CRT, chemoradiotherapy; EBRT, external beam radiation therapy; $\mathrm{BT}$, brachytherapy; 5FU, 5-fluorouracil; PFS, progressive-free survival. 
have stated that the OS is better with the addition of RT to chemotherapy [31,32]. Bisello et al. [33] in a single institute retrospective study, have stated that CRT is a feasible option in cases of unresectable GBC. They had given a median external beam radiation therapy (EBRT) dose of $50 \mathrm{~Gy}$ with a BT boost of $14 \mathrm{~Gy}$ along with 5-fluorouracil (5FU)/gemcitabine-based chemotherapy.

Very few studies have thus evaluated the role of definitive radiation therapy in GBC. The paucity of patients, poor general condition, and advanced stage at presentation could be some of the possible reasons for it. Although initially considered as a radioresistant tumor, the above-mentioned studies support its usage. Hence trials whenever feasible should be conducted to establish the role of definitive RT.

\section{Palliative Radiotherapy}

GBC is usually present in locally advanced or metastatic stages, and thus the treatment offered for such patients is palliative chemotherapy or best supportive care (BSC) only [34]. The goals of palliation usually include relief of pain, jaundice, bowel obstruction, and improving quality of life. Palliative RT is well known to provide relief from local symptoms in patients with various malignancies [35]. The role of palliative RT in GBC is less explored and chemotherapy is the primary palliative therapy.

Eleftheriadis et al. [36] have reported a case of unresectable GBC who has received RT alone. The patient had stable disease at 12 months post-RT. Singh et al. [37] have retrospectively compared BSC alone with chemotherapy and CRT. Fifty patients were includ- ed in the analysis. The chemotherapy given was gemcitabine injection $800 \mathrm{mg} / \mathrm{m}^{2}$ and oxaliplatin injection $80 \mathrm{mg} / \mathrm{m}^{2}$ (mGEMOX) given every 2 weekly for 6 cycles and the RT was 30-45 Gy in 1025 fractions depending on the performance score of the patient. The PFS of patients who received BSC at 18 months was 10\%, chemotherapy alone was $28 \%$ and with CRT it was 38\%.

Transhepatic percutaneous intraluminal brachytherapy using ${ }^{192} \mathrm{Ir}$ has been used as palliative therapy for obstructive jaundice due to bile duct obstruction $[38,39]$. Thus, the addition of palliative RT to unresectable disease has the potential to improve the PFS and provide symptomatic relief in unresectable GBC. Prospective trials are required to further evaluate the role of palliative $R T$.

In short, the role of palliative radiotherapy in $\mathrm{GBC}$ still needs to be explored. It could be well utilized in this group of patients, especially in patients who are not fit for chemotherapy and presents with jaundice and pain.

\section{Role in Neoadjuvant Therapy}

Neoadjuvant therapy improves the rate of resection by downstaging the tumor, improving the operability of the tumor. The role of radiation in $\mathrm{GBC}$ in the neoadjuvant setting has been considered to be in a trial setting only (Table 3). de Aretxabala et al. [40] in a prospective study using neoadjuvant CRT in GBC patients, have stated that there was no benefit of using neoadjuvant $R T$ in unresectable GBC and patients had a worse survival with neoadjuvant therapy. Agrawal et al. [41] have prospectively studied the benefit of neoadjuvant CRT in 40 patients of unresectable GBC. RT of 45 Gy in 25

Table 3. Studies showing role of neoadjuvant RT

\begin{tabular}{|c|c|c|c|c|c|}
\hline Study, year & Type & $\mathrm{n}$ & Characteristic & Treatment received & Outcomes \\
\hline $\begin{array}{l}\text { de Aretxabala et al. [40], } \\
2004\end{array}$ & Prospective & 23 & $\begin{array}{l}\text { Subserosal infiltration: } 18(82 \%) \\
\text { Serosal infiltration: } 3 \text { (13\%) } \\
\text { Adipose tissue infiltration: } 2 \text { (9\%) }\end{array}$ & $\begin{array}{l}\text { RT dose } 45 \mathrm{~Gy} / 25 \text { fractions, con- } \\
\text { current } 5 \mathrm{FU} \text { initially } 500 \mathrm{mg} / \mathrm{m}^{2} \\
\text { then reduced to } 350 \mathrm{mg} / \mathrm{m}^{2} \\
\text { (d1-d5 and d28-d32) }\end{array}$ & $\begin{array}{l}\text { No positive effect seen with } \\
\text { chemoradiation }\end{array}$ \\
\hline Aggarwal et al. [41], 2016 & Prospective & 40 & $\begin{array}{l}\text { Hilum involvement: } 19 \text { (47.5\%), } \\
\text { Liver infiltration (any): } 38 \text { (95\%) } \\
\text { Liver infiltration> } 2 \text { cm: } 28 \text { (70\%) } \\
\text { Duodenum involvement: } 22(55 \%) \\
\text { Colon involvement: } 11(27.5 \%) \\
\text { N1: } 11(27.5 \%) \\
\text { N2: } 8 \text { (20\%) } \\
\text { Para-aortic LN: } 15(37.5 \%)\end{array}$ & $\begin{array}{l}\text { RT dose } 45 \text { Gy } / 25 \text { fractions, con- } \\
\text { current (weekly cisplatin } 35 \\
\mathrm{mg} / \mathrm{m}^{2}+5 \text { FU } 500 \mathrm{mg} / \mathrm{m}^{2} \text { ) and } \\
\text { NACT (cisplatin } 25 \mathrm{mg} / \mathrm{m}^{2} \text { and } \\
\text { gemcitabine } 1 \mathrm{~g} / \mathrm{m}^{2}, 3 \text { weekly) } \\
\text { in patients with para-aortic in- } \\
\text { volvement }\end{array}$ & $\begin{array}{l}\text { 1/6 }(16.6 \%) \text { showed pCR of } \\
\text { primary, while } 5 / 6(83.3 \%) \\
\text { showed pCR of lymph nodes }\end{array}$ \\
\hline Engineer et al. [42], 2016 & Prospective & 28 & Stage III (100\%) & $\begin{array}{l}\text { RT } 57 \mathrm{~Gy} / 25 \text { fractions to the pri- } \\
\text { mary and } 45 \mathrm{~Gy} / 25 \text { fractions to } \\
\text { the lymph nodes, concurrent } \\
\text { gemcitabine } 300 \mathrm{mg} / \mathrm{m}^{2}\end{array}$ & $\begin{array}{l}\text { Median OS: } 20 \text { months } \\
\text { 5-yr survival rate: for all pa- } \\
\text { tients }(24 \%), \text { and for } 14 / 25 \\
\text { patients with R0 resection } \\
(47 \%)\end{array}$ \\
\hline
\end{tabular}

RT, radiotherapy; OS, overall survival; 5FU, 5-fluorouracil; NACT, neoadjuvant chemotherapy; pCR, pathological complete response; LN, lymph node. 
fractions along with concurrent 5FU and cisplatin were given. Neoadjuvant chemotherapy was given before RT if the patient was node-positive. They concluded that neoadjuvant therapy resulted in a 15\% resectability rate with a radiological downstaging of liver involvement in $40 \%$ of the patients and downstaging of lymph nodes in 67.5\%. Engineer et al. [42] prospectively studied 28 patients of locally advanced GBC of T3/T4 with large fixed periportal nodes. In their study, patients were given 57 Gy to the gross tumor and $45 \mathrm{~Gy}$ to the clinical target volume (CTV) in 25 fractions along with weekly gemcitabine of $300 \mathrm{mg} / \mathrm{m}^{2}$. Eighteen patients were surgically explored and 14 patients underwent Ro resection. Twenty patients had achieved a complete or partial response. The median OS was 20 months.

High rates of biliary stricture and biliary leak were reported in patients receiving neoadjuvant therapy [43]. There is insufficient data regarding the use of RT in the neoadjuvant setting and the benefit of resectability has been seen in a third of the patients in a pooled analysis of eight studies conducted by Hakeem et al. [44]. Perioperative therapy in locally advanced gallbladder cancers (POLCAGB) trial is an ongoing phase 3 trial that is comparing the OS, PFS, resection rates, and toxicities between patients receiving neoadjuvant chemotherapy and neoadjuvant CRT [45]. Though some of the RT studies done in patients of GBC so far support its usage in the neoadjuvant setting, more and more collaborative studies are still warranted.

\section{Conclusion}

This article provides an updated overview of the role of RT in GBC in its various formats. As the local failure is high in GBC, RT has a good potential in reducing the local failures in the adjuvant setting. Future usage of advanced techniques might help in providing dose escalation to the tumor site with better sparing of OARs. Definitive $\mathrm{RT}$ in patients of unresectable GBC is an area for potential clinical research. Palliative RT too remains investigational, which otherwise could be utilized to reduce the local disease progression and provide symptomatic relief in unresectable cases. Lastly, the use of neoadjuvant therapy to downstage the disease and improve resectability still remains in its preliminary phase which needs further evaluation. Overall, with the paucity of literature supporting the usage of modern techniques of RT in $\mathrm{GBC}$, the role of RT needs to be further enhanced and improved in quality.

\section{Conflict of Interest}

No potential conflict of interest relevant to this article was reported.

\section{References}

1. Fong $Y$, Wagman $L$, Gonen $M$, et al. Evidence-based gallbladder cancer staging: changing cancer staging by analysis of data from the National Cancer Database. Ann Surg 2006;243:767-74.

2. Duffy A, Capanu M, Abou-Alfa GK, et al. Gallbladder cancer (GBC): 10-year experience at Memorial Sloan-Kettering Cancer Centre (MSKCC). J Surg Oncol 2008;98:485-9.

3. Marcano-Bonilla L, Mohamed EA, Mounajjed T, Roberts LR. Biliary tract cancers: epidemiology, molecular pathogenesis and genetic risk associations. Chin Clin Oncol 2016;5:61.

4. Sung H, Ferlay J, Siegel RL, et al. Global Cancer Statistics 2020: GLOBOCAN estimates of incidence and mortality worldwide for 36 cancers in 185 countries. CA Cancer J Clin 2021;71:209-49.

5. Jarnagin WR, Ruo L, Little SA, et al. Patterns of initial disease recurrence after resection of gallbladder carcinoma and hilar cholangiocarcinoma: implications for adjuvant therapeutic strategies. Cancer 2003;98:1689-700.

6. Kopelson G, Galdabini J, Warshaw AL, Gunderson LL. Patterns of failure after curative surgery for extra-hepatic biliary tract carcinoma: implications for adjuvant therapy. Int J Radiat Oncol Biol Phys 1981;7:413-7.

7. Bosset JF, Mantion G, Gillet M, et al. Primary carcinoma of the gallbladder: adjuvant postoperative external irradiation. Cancer 1989;64:1843-7.

8. Kresl JJ, Schild SE, Henning GT, et al. Adjuvant external beam radiation therapy with concurrent chemotherapy in the management of gallbladder carcinoma. Int J Radiat Oncol Biol Phys 2002;52:167-75.

9. Lindell G, Holmin T, Ewers SB, Tranberg KG, Stenram U, Ihse I. Extended operation with or without intraoperative (IORT) and external (EBRT) radiotherapy for gallbladder carcinoma. Hepatogastroenterology 2003;50:310-4.

10. Czito BG, Hurwitz HI, Clough RW, et al. Adjuvant external-beam radiotherapy with concurrent chemotherapy after resection of primary gallbladder carcinoma: a 23-year experience. Int J Radiat Oncol Biol Phys 2005;62:1030-4.

11. Balachandran P, Agarwal S, Krishnani N, et al. Predictors of longterm survival in patients with gallbladder cancer. J Gastrointest Surg 2006;10:848-54.

12. Gold DG, Miller RC, Haddock MG, et al. Adjuvant therapy for gallbladder carcinoma: the Mayo Clinic experience. Int J Radiat Oncol Biol Phys 2009;75:150-5.

13. Kim K, Chie EK, Jang JY, et al. Postoperative chemoradiotherapy for gallbladder cancer. Strahlenther Onkol 2012;188:388-92.

14. Muller B, Sola JA, Carcamo M, Ciudad AM, Trujillo C, Cerda B. Adjuvant chemoradiation for resected gallbladder cancer: treat- 
ment strategies for one of the leading causes of cancer death in Chilean women. Indian J Cancer 2013;50:184-8.

15. Jeong Y, Park JH, Lee YJ, et al. Postoperative radiotherapy for gallbladder cancer. Anticancer Res 2014;34:5621-9.

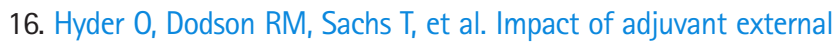
beam radiotherapy on survival in surgically resected gallbladder adenocarcinoma: a propensity score-matched surveillance, epidemiology, and end results analysis. Surgery 2014;155:85-93.

17. Wang J, Narang AK, Sugar EA, et al. Evaluation of adjuvant radiation therapy for resected gallbladder carcinoma: a multi-institutional experience. Ann Surg Oncol 2015;22 Suppl 3:S1100-6.

18. Ben-Josef E, Guthrie KA, El-Khoueiry AB, et al. SWOG S0809: a phase II intergroup trial of adjuvant capecitabine and gemcitabine followed by radiotherapy and concurrent capecitabine in extrahepatic cholangiocarcinoma and gallbladder carcinoma. J Clin Oncol 2015;33:2617-22.

19. Kim Y, Amini N, Wilson A, et al. Impact of chemotherapy and external-beam radiation therapy on outcomes among patients with resected gallbladder cancer: a multi-institutional analysis. Ann Surg Oncol 2016;23:2998-3008.

20. Mantripragada KC, Hamid F, Shafqat H, Olszewski AJ. Adjuvant therapy for resected gallbladder cancer: analysis of the National Cancer Data Base. J Natl Cancer Inst 2016;109:djw202.

21. Kim BH, Kwon J, Chie EK, et al. Adjuvant chemoradiotherapy is associated with improved survival for patients with resected gallbladder carcinoma: a systematic review and meta-analysis. Ann Surg Oncol 2018;25:255-64.

22. Ren B, Guo Q, Yang $Y$, et al. A meta-analysis of the efficacy of postoperative adjuvant radiotherapy versus no radiotherapy for extrahepatic cholangiocarcinoma and gallbladder carcinoma. Radiat Oncol 2020;15:15.

23. Kapoor R, Periasamy K, Gupta R, Yadav A, Khosla D. Real world clinical outcomes of adjuvant sequential chemoradiation in patients with gallbladder carcinomas with poor performance status. Radiat Oncol J 2020;38:262-9.

24. Chen $X$, Meng F, Xiong $H_{1}$ Zou Y. Adjuvant therapy for resectable biliary tract cancer: a Bayesian network analysis. Front Oncol 2021;11:600027.

25. Fuller CD, Thomas CR Jr, Wong $A$, et al. Image-guided intensity-modulated radiation therapy for gallbladder carcinoma. Radiother Oncol 2006;81:65-72.

26. Gedam VR, Pradhan A. Dosimetric comparison of constant dose rate volumetric modulated arc therapy (CDR-VMAT) and intensity-modulated radiation therapy (IMRT) for gallbladder cancer. Journal of Radiotherapy in Practice 2020 Dec 29 [Epub]. https:// doi.org/10.1017/S1460396920001132.

27. Kurisu K, Hishikawa Y, Taniguchi M, et al. High-dose-rate intralu- minal brachytherapy for postoperative residual tumor of gallbladder carcinoma: a case report. Radiat Med 1991;9:241-3.

28. Mahadevan A, Dagoglu N, Tseng JF, Khawaja K, Evenson A. Therapeutic potential of adjuvant stereotactic body radiotherapy for gallbladder cancer. Cureus 2015;7:e299.

29. Jung YH, Choi HS, Cheon YK, et al. An experience of cyberknife treatment in patients with advanced pancreaticobiliary malignancy. Korean J Gastroenterol 2011;58:264-9.

30. Makita C, Nakamura T, Takada A, et al. Clinical outcomes and toxicity of proton beam therapy for advanced cholangiocarcinoma. Radiat Oncol 2014;9:26.

31. Pollom EL, Alagappan M, Park LS, Whittemore AS, Koong AC, Chang DT. Does radiotherapy still have a role in unresected biliary tract cancer? Cancer Med 2017;6:129-41.

32. Verma V, Surkar SM, Brooks ED, Simone CB 2nd, Lin C. Chemoradiotherapy versus chemotherapy alone for unresected nonmetastatic gallbladder cancer: national practice patterns and outcomes. J Natl Compr Canc Netw 2018;16:59-65.

33. Bisello S, Buwenge M, Palloni A, et al. Radiotherapy or Chemoradiation in unresectable biliary cancer: a retrospective study. Anticancer Res 2019;39:3095-100.

34. Perpetuo MD, Valdivieso M, Heilbrun LK, Nelson RS, Connor T, Bodey GP. Natural history study of gallbladder cancer: a review of 36 years experience at M. D. Anderson Hospital and Tumor Institute. Cancer 1978:42:330-5.

35. Kumar A, Mukundan H, Bhatnagar S, Sarin A, Taneja S, Sahoo S. Radiation for palliation: role of palliative radiotherapy in allevieating pain/symptoms in a prospective observational study at two tertiary care centers. Indian J Palliat Care 2019;25:391-7.

36. Eleftheriadis N, Pistevou-Gombaki K, Plataniotis G, Sofroniadis I, Kouloulias V. Is external palliative radiotherapy for gallbladder carcinoma effective? Onkologie 2001;24:581-4.

37. Singh PK, Kapoor R, Kumar R, et al. Best supportive care compared with chemotherapy and radiotherapy for unresectable gallbladder cancer: a tertiary care institute experience. Clin Cancer Investig J 2014;3:153-6.

38. Aggarwal R, Patel FD, Kapoor R, Kang M, Kumar P, Chander Sharma S. Evaluation of high-dose-rate intraluminal brachytherapy by percutaneous transhepatic biliary drainage in the palliative management of malignant biliary obstruction: a pilot study. Brachytherapy 2013;12:162-70.

39. Jain S, Kataria T, Bisht SS, et al. Malignant obstructive jaundice: brachytherapy as a tool for palliation. J Contemp Brachytherapy 2013;5:83-8.

40. de Aretxabala X, Losada H, Mora J, et al. Neoadjuvant chemoradiotherapy in gallbladder cancer. Rev Med Chil 2004;132:51-7.

41. Agrawal S, Mohan L, Mourya C, Neyaz Z, Saxena R. Radiological 
downstaging with neoadjuvant therapy in unresectable gall bladder cancer cases. Asian Pac J Cancer Prev 2016;17:2137-40.

42. Engineer R, Goel M, Chopra S, et al. Neoadjuvant chemoradiation followed by surgery for locally advanced gallbladder cancers: a new paradigm. Ann Surg Oncol 2016;23:3009-15.

43. Loyal A, Chopra S, Goel M, et al. Predictors of toxicity after neoadjuvant chemoradiotherapy for locally advanced gall bladder cancer. Indian J Cancer 2021 Jan 27 [Epub]. https://doi.org/10.
4103/ijc.IJC_822_19.

44. Hakeem AR, Papoulas M, Menon KV. The role of neoadjuvant chemotherapy or chemoradiotherapy for advanced gallbladder cancer: a systematic review. Eur J Surg Oncol 2019;45:83-91.

45. Engineer R, Patkar S, Lewis SC, et al. A phase III randomised clinical trial of perioperative therapy (neoadjuvant chemotherapy versus chemoradiotherapy) in locally advanced gallbladder cancers (POLCAGB): study protocol. BMJ Open 2019;9:e028147. 